\title{
Classroom Communication Techniques: A Tool for Pupils' Participation in the Learning Process across the Curriculum
}

\author{
Kibinkiri Eric Len \\ Department of Science of Education, Higher Teacher Training College Yaounde (E.N.S), University of Yaounde I, Yaounde, \\ Cameroon \\ Email: kibinkirieric@yahoo.com
}

How to cite this paper: Len, K. E. (2018). Classroom Communication Techniques: A Tool for Pupils' Participation in the Learning Process across the Curriculum. Creative Education, 9, 535-548.

https://doi.org/10.4236/ce.2018.93037

Received: February 13, 2018

Accepted: March 27, 2018

Published: March 30, 2018

Copyright $\odot 2018$ by author and Scientific Research Publishing Inc. This work is licensed under the Creative Commons Attribution International License (CC BY 4.0).

http://creativecommons.org/licenses/by/4.0/

\begin{abstract}
This study investigated "how classroom communication techniques can influence pupils' participation in the learning process". The inability of pupils to acquire basic competences in some primary schools in Cameroon due to the persistent use of inappropriate teaching behaviours by teachers moved the researcher to carry out this study. The study aims to answer the question "To what extent does classroom communication techniques influences pupils' participation in the learning process?" Related literature was reviewed based on classroom communication techniques and pupils' participation in the learning process. The theories which were used to give more meaning to the problem of study include socio-constructivism by Lev Vygotsky, the social learning theory by Albert Bandura and the theory of cognitive development by Jean Piaget. The qualitative approach was applied to carry out the study. Observation and Interview methods were used. Data was collected using a structured Observation guide and a semi interview guide. The population of the study was made up of primary school teachers of Government Bilingual Pramary School Mballa IV Group I, Mfoundi Division, Yaounde. From this population, five teachers from level one (classes one and two) were selected for the study through non probability sampling technique. The data collected were analysed thematically following the objectives of the study. Overall, results of this study revealed that classroom communication techniques influence pupils' participation in the learning process. Recommendations are made to teachers to use appropriate communication behaviours in the classroom in order to improve learners' participation in the learning process.
\end{abstract}

\section{Keywords}

Communication Techniques, Participation, Learning Process, Non-Verbal Communication, Verbal Communication, Written Communication 


\section{Introduction}

Education is a process which brings positive changes in the behaviour, character, skills and knowledge of the learners. The classroom is the main social venue in the school where pupils are expected to acquire and develop new knowledge, skills and competences. The teacher being the main actor in the school plays a key role in the classroom in modifying the modes of thinking among students. In this regard, classroom communication towards purposeful direction is quite necessary for the success and fecundity of the learning process. Teachers have as responsibility to communicate to/with the learners, thus creating social interactions in the classroom. These interactions during the lesson can influence the outcome of the learning process. Thus, the success of every child to acquire quality education can depend to a large extent on the way the teacher manages communication strategies and techniques with the learners in the classroom. Teachers communicate with the learners in different ways. Communication with learners can take place verbally, non-verbal and written. These communication behaviours can create different meanings and interactions within and among the learners. The first step in problem-solving is identification of the problem. The meanings learners derive from observations and teacher communication can influence their problem-solving capabilities. This corroborates the insight that classroom communication can have an influence on learners' participation in the learning process. Considering that learners in the classroom come from different family backgrounds, cultures and religion with different expectations and needs, teachers have to be aware of the relevance and implications of classroom communication. Communication techniques have the potential to address the diverse needs of the learners in the classroom.

Moreover, classroom communication can support and determine the effective implementation of the curriculum, specific strategies and methods of teaching. From the global perspective, curriculum implementation paradigms have evolved from teacher centred, learner centred and activity based. This has also influenced the roles of the teacher in the classroom from being the sole proprietor of knowledge to roles like facilitator, motivator, collaborator, supervisor, observer, trainer, consultant, manager, and organizer. Cameroon has not been left out as far as these transformations are concerned in the teaching learning process. The country has experienced a shift from the objective based approach to the competency based approach. The objective based approach in teaching focuses on behavioural changes in the learner. It places a lot of emphasis on knowledge acquisition. Whereas the competency based approach focuses on the competence to be developed and lay emphasis on the skills and the competences to be developed. This approach is learner centred and builds on mastery learning and problem solving. The main official languages used for instruction in schools are English Language and French Language since Cameroon is a bilingual country. The country runs two systems of education; the French sub-system of Education and the English sub-system of education respecting the dual heritage of 
the country (Ministry of National Education, 2000).

The problem envisaged by this study is how to improve pupils' participation in the learning process by helping teachers adopt proper classroom communication techniques in the classroom. The inability of pupils to acquire basic competences in some primary schools in Cameroon due to the persistent use of inappropriate teaching techniques by teachers moved the researcher to carry out this study. World Bank (2018) stressed that countries are failing to provide learning for all. It points out that children from poor households in Africa typically learn much less. Teacher behaviours and predispositions in the classroom to an extent contribute to poor learning outcomes and standards. It is important to underline that children need accurate and maximum communication from parents and teachers during early childhood years. Bredekamp and Copple (1997) underscore that rich and appropriate communication helps all areas of children's development.

\section{Literature Review}

\subsection{Conceptual Framework}

In our study, classroom communication refers to specific actions and discourse that take place within a lesson and that physically enact teaching approaches and strategies. Communication strategies in this work include non-verbal communication, verbal communication or oral communication and written communication. Bottino (2004) propagates that School curricular includes different types of teaching and learning methods and there is no single method or type of tool that can be used for all occasions. Moreover, within any learning domain, students' and teachers' needs evolve during the activities in which they are involved and so teaching methods, techniques and tools have to support this evolution. The teacher need to use his or her own problem-solving abilities to identify, choose, and determine the most appropriate communication behaviours and interpersonal approaches to use with the learner (Glickman, 1985).

In addition, non-verbal communication in the classroom in our study has as its basis that learning is principally an individualized experience in which kids come up with their own solutions to problems during the teaching learning process. The role of the teacher is to listen and construct gestures such as staring, beckoning and body movements (kinetics), make clarifications with proxemics such as hand signals, charts, sand tray, shopping corner and real objects. In the course of the lesson, frequency of the aforementioned processes including eye contact, timing of questions, and ways of paraphrasing can be interpreted by a teacher as approving or disapproving.

Also, verbal communication in the classroom in this study is a technique based on the premise that teaching consists of problem-solving and sharing of ideas which defines effective teaching and learning. Verbal communication behaviors are used to inform and share knowledge with the learners clearly. The aspects considered include speech (clarity, duration, confidence, art of listening) 
during the teaching learning process. Verbal communication consists of behaviours of presenting, directing, guiding, clarifying, explaining, describing, listening and evaluating. According to Kauchak and Eggen (1998), learner discussions in the classroom can stimulate thinking, challenge attitudes, beliefs and develop interpersonal skills. Discussion in the classroom is a democratic process whereby each learner is given equal opportunity to interact and put forth their views. Classroom discussion can take different forms for example panel, buzz sessions, forum and whole class discussion. The teacher asks and answer questions, make clarifications, presents summaries during classroom discussions (Tambo, 2012).

More still, written communication in the classroom in the study is based on the belief that teaching consists of technical skills and professional competences which defines effective teaching and learning. Written communication behaviors are used to transmit the teacher's expectations to the learners clearly. The teacher makes use of visual representations using the chalkboard, writing, learning aids, diagrams, pictures, textbook to construct new knowledge or understanding. The teacher takes care of issues of grammar (use of nouns, verbs, adverbs, prepositions etc.) and punctuations (colons, hyphens, apostrophes, point etc.). Little (1982) in Glickman (1985) point out that teachers in successful schools use precise, technical language in discussing instructional concerns and continue to think and are challenged to extend the use of their mental abilities.

\subsection{Theoretical Framework}

\subsubsection{Socio-Constructivism by Lev Vygotsky}

The socio-constructivist theory is important and can be applied to classroom communication and participation in the learning process. Initially, socioconstructivism became influential in education through the works of Lev Vygotsky. Constructivism has laid the foundation for teaching practices used in contemporary inclusive classrooms. Wang (2009) pointed out that the Russian psychologist Lev Vygotsky is best known for proposing the sociocultural theory of cognitive development. Vygotsky's theory states that interacting with others is an important key in the learning process because human minds develop through their interaction with society Wang (2009). According to Tu (2000), Vygotsky's theory, "full cognitive development requires social interaction. The socioconstructivist theory helps us to understand how people learn in social contexts and inform us on how the teacher can construct active learning communities through interactions and communications with others. Modern teaching strategies are deeply rooted in theories of constructivism. According to the constructivists, in order for learning to occur, people must independently discover and transform complex information for understanding (Brown, Collins, \& Duguid, 1989). Vygotsky introduced the concept of the zone of proximal development from his research on sociocultural theory of cognitive development, which examined the effect of social interactions on children. The zone of proximal development is the difference between what children can do with assistance and 
what they can do alone (Kail \& Cavanaugh, 2010). Vygotsky believed that authentic learning occurs while children work within their zone of proximal development.

\subsubsection{Social Learning Theory by Albert Bandura}

The social learning theory is relevant to classroom communication and learners' participation in the learning process. Bandura recognised the importance of socialisation in the learning process. Observation and modelling are central to Bandura's theory as "most human behaviour is learned observationally through modelling: from observing others one forms an idea of how new behaviours are performed, and on later occasions this coded information serves as a guide for action" (Bandura, 1977). The concept of self-efficacy is a component of Bandura's social learning theory. Self-efficacy can be defined as human belief in students' ability to achieve goals, form friendships, and or gain status (Ellis, \& Abrams, 2009). Self-efficacy determines how much effort people will put in overcoming an obstacle (Bandura, 1997). Bandura's theory of social learning closes the gap between behavioural and cognitive learning theories by taking into account how imitable behaviours are affected by cognitive constructs such as attention, retention and motivation (Bandura, 1977). Much learning occurs when children observe, model and imitate models. With this, they can retain knowledge by observing and modelling the desired behaviours, attitudes and reactions of others due to the fact that human thought processes are central to understanding personality. Participatory learning can be realised through classroom communication. Wenger (1998) cited in Crook (2001) states that such ventures illustrate a route towards greater participatory experience that is based upon creating authentic "communities of practice". On his part, Tisdell (2005) stressed the "connections between individuals and social structures and notions of intersecting personalities". The goal of this approach is to foster interaction, storytelling on a personal and social level through group inquiry.

\subsubsection{The Theory of Cognitive Development by Jean Piaget}

The theory of cognitive development by Jean Piaget explains how children learn. This theory is relevant and can be applied to classroom communication techniques and pupils participation in the learning process. To Piaget, children between 7 and 11 years are in the concrete stage of cognitive development (Santrock, 2004). According to him, at this stage, the child begins to develop abstract thought and abilities to make rational judgments. Accommodation greatly increases as the stage increases. Children in primary schools in Cameroon are in the concrete stage of cognitive development. In this stage, Piaget explains that children can mentally process information received from the environment through observations and solve real and complex problems (Santrock, 2004). A lot of research has been carried out on the potentials of communication in business and other developmental agencies. But much is still to be known about classroom communication techniques and pupils' participation in the learning 
process. This study aims to answer the following research questions:

\section{General Research Question}

To what extent does classroom communication techniques influences pupils participation in the learning process?

Specific Research Questions

How does non-verbal communication influence pupils participation in the learning process?

How can verbal communication contribute to pupils participation in the learning process?

How can written communication stimulate pupils participation in the learning process?

\section{Research Methodology}

The study was carried out in Cameroon specifically in Yaounde, Mfoundi Division with teachers of classes one and two of Government Bilingual Primary School Mballa IV Group I. This school was created in 1989. It received its first pupils in September, 1994. It is purely an Anglo-Saxon institution with the English Language as the main medium of instruction. The school has French Language teachers who teach learners the French Language as a discipline in the curriculum. The school has a population of six hundred and twenty one (621) pupils. The success of G.B.P.S Group I Mballa IV lies on the professionalism of her personnel. It has eight (8) trained teachers, two (2) French Language teachers, a head teacher and other support staff. The choice of G.B.P.S Mballa IV Group I was based on the characteristics possessed by this institution which suit the problem under study. The population of the study was made up of primary school teachers. The sample was made up of five (5) teachers drawn from class one and two, level one of the primary school. Purposive sampling technique was used to select the teachers. This was partly based on their prior experiences in the field. Those who have worked for five years and above were selected. These teachers are the main actors in the teaching and learning process in the classroom. They use a variety of teaching strategies, methods and techniques in their large class sizes. World Bank (2018) report that teacher quality is an important factor in determining gains in learner achievement. The table below presents the socio-demographic characteristics of the participants:

As shown on Table 1, the participants were named Teacher 1, Teacher 2, Teacher 3, Teacher 4 and Teacher 5. Out of the five teachers who took part in the study, four were female and one male. The ages of these teachers ranged from 39 years to 50 years. All the participants had a teachers' grade I certificate. Their work experiences ranged from 8 years to 10 years. The methods used for data collection were observation and interview. A semi structured observation guide and semi structured interview guide were constructed with respect to the objectives of the study and applied respectively to collect data. The content of the interview and the observation consisted of three main parts. The observation 
Table 1. Socio-demographic characteristics of the participants.

\begin{tabular}{ccccccc}
\hline Teachers & Gender & Grade & Diploma & Experience & Class & Age \\
\hline Teacher 1(T1) & Female & IC1 & CAPIEMP & 10 years & One & 48 years \\
Teacher 2(T2) & female & IC2 & CAPIEMP & 10 years & One & 41 years \\
Teacher 3(T3) & Male & IC3 & CAPIEMP & 9 years & Two & 45 years \\
Teacher 4(T4) & Female & IC1 & CAPIEMP & 10 years & Two & 50 years \\
Teacher 5(T5) & Female & IC4 & CAPIEMP & 8 years & Two & 39 years \\
\hline
\end{tabular}

guide was adapted from Ned A. Flanders (1985) cited in Reed and Bergemann (1995: p. 16). The variables presented in the instruments include non-verbal communication, verbal communication or oral communication and written communication. These constructs were designed with respect to participation in the learning process. Interviews gave the teachers the opportunity to express themselves freely. It also helped the researcher to have face to face and verbal interactions with the participants. Observations helped the researcher to collect real and firsthand information about the teachers with the students in their classrooms. Each observation took a maximum of 30 minutes. Interview also had a maximum duration of 30 minutes. These processes took place from January to May, 2017. The teacher of class three in the school called Bitmia Florence Titafanserved as the main focal point of our project. She assisted the researcher in the data collection process.

The data collection process began with a presentation of the project and the researchers to the participants. Confidentiality of participants and information collected was assured. Interviews were carried out in the Classrooms after school when kids have gone back home. Information provided was recorded with the aid of a multimedia phone and a note book. The different interviews were transcribed. Transcription was done by listening carefully to the audio recordings and writing down every word that was used by the teacher. The process was repeated to avoid the error of leaving out vital information. The transcribed interviews were typed and crosschecked as many times as possible to ensure that all the relevant information was presented. Questions and comments which resulted from informal talks were also taken into consideration. Data collected were analysed using content analysis. This was done with respect to the themes and sub-themes which defined the study.

\section{Presentation of Findings}

\subsection{Findings of Observation}

Table 2 presents the general results of observation on classroom communication and pupils' participation in the learning process.

The overall analysis of observation on classroom communication and pupils' participation in the learning process revealed interesting results. Results as can be seen on Table 2 and on Figure 1 shows that nonverbal communication had 
Table 2. General results of observation on classroom communication and pupils' participation in the learning process.

\begin{tabular}{|c|c|c|c|c|c|c|c|c|c|c|}
\hline \multirow[t]{2}{*}{ Themes } & \multirow[t]{2}{*}{ Sub themes } & \multirow[t]{2}{*}{ Elements Observed } & \multicolumn{5}{|c|}{ PARTICIPANTS (T) } & \multirow{2}{*}{$\begin{array}{c}\text { Total } \\
\text { Frequency }\end{array}$} & \multirow{2}{*}{$\begin{array}{l}\text { Percentage } \\
\text { (\%) }\end{array}$} & \multirow{2}{*}{$\begin{array}{c}\text { Total per } \\
\text { theme }\end{array}$} \\
\hline & & & $\mathrm{T} 1$ & $\mathrm{~T} 2$ & T3 & $\mathrm{T} 4$ & T5 & & & \\
\hline \multirow[t]{9}{*}{$\begin{array}{c}\text { Non Verbal } \\
\text { Communication }\end{array}$} & Kinetics & Gesture & 9.00 & 9.00 & 7.00 & 9.00 & 4.00 & 38.00 & 6.95 & \\
\hline & & Staring & 5.00 & 4.00 & 5.00 & 5.00 & 7.00 & 26.00 & 4.75 & \\
\hline & & Beckoning & 9.00 & 6.00 & 8.00 & 9.00 & 3.00 & 35.00 & 6.40 & \\
\hline & & Body movements & 8.00 & 10.00 & 7.00 & 8.00 & 9.00 & 42.00 & 7.68 & \\
\hline & Proxemics & Hand signals & 9.00 & 7.00 & 4.00 & 5.00 & 8.00 & 33.00 & 6.03 & \\
\hline & & Charts & 7.00 & 7.00 & 4.00 & 4.00 & 9.00 & 31.00 & 5.67 & \\
\hline & & Sand tray & 2.00 & 2.00 & 5.00 & 2.00 & 2.00 & 13.00 & 2.38 & \\
\hline & & Shopping corner & 2.00 & 3.00 & 9.00 & 2.00 & 1.00 & 17.00 & 3.11 & \\
\hline & & Real Objects & 8.00 & 9.00 & 7.00 & 8.00 & 7.00 & 39.00 & 7.13 & 50.09 \\
\hline \multirow[t]{4}{*}{$\begin{array}{c}\text { Verbal } \\
\text { Communication }\end{array}$} & Speech & Clarity & 6.00 & 5.00 & 8.00 & 8.00 & 4.00 & 31.00 & 5.67 & \\
\hline & & Duration & 4.00 & 8.00 & 5.00 & 7.00 & 4.00 & 28.00 & 5.12 & \\
\hline & & Confidence & 8.00 & 10.00 & 5.00 & 9.00 & 5.00 & 37.00 & 6.76 & \\
\hline & & art of listening & 9.00 & 8.00 & 7.00 & 8.00 & 3.00 & 35.00 & 6.40 & 23.95 \\
\hline \multirow[t]{9}{*}{$\begin{array}{c}\text { Written } \\
\text { Communication }\end{array}$} & Grammar & use of Nouns & 7.00 & 5.00 & 4.00 & 8.00 & 7.00 & 31.00 & 5.67 & \\
\hline & & use of Verbs & 4.00 & 3.00 & 2.00 & 7.00 & 4.00 & 20.00 & 3.66 & \\
\hline & & use of Adverbs & 3.00 & 4.00 & 2.00 & 2.00 & 4.00 & 15.00 & 2.74 & \\
\hline & Punctuation & Parentheses & 4.00 & 3.00 & 4.00 & 2.00 & 4.00 & 17.00 & 3.11 & \\
\hline & & Colons & 5.00 & 7.00 & 7.00 & 4.00 & 5.00 & 28.00 & 5.12 & \\
\hline & & Hyphens & 2.00 & 3.00 & 3.00 & 3.00 & 4.00 & 15.00 & 2.74 & \\
\hline & & Apostrophes & 1.00 & 4.00 & 4.00 & 4.00 & 3.00 & 16.00 & 2.93 & 25.96 \\
\hline & Total & & 112.00 & 117.00 & 107.00 & 114.00 & 97.00 & 547.00 & 100.00 & 100 \\
\hline & Tota & percentage & 20.48 & 21.39 & 19.56 & 20.84 & 17.73 & 100.00 & & \\
\hline
\end{tabular}

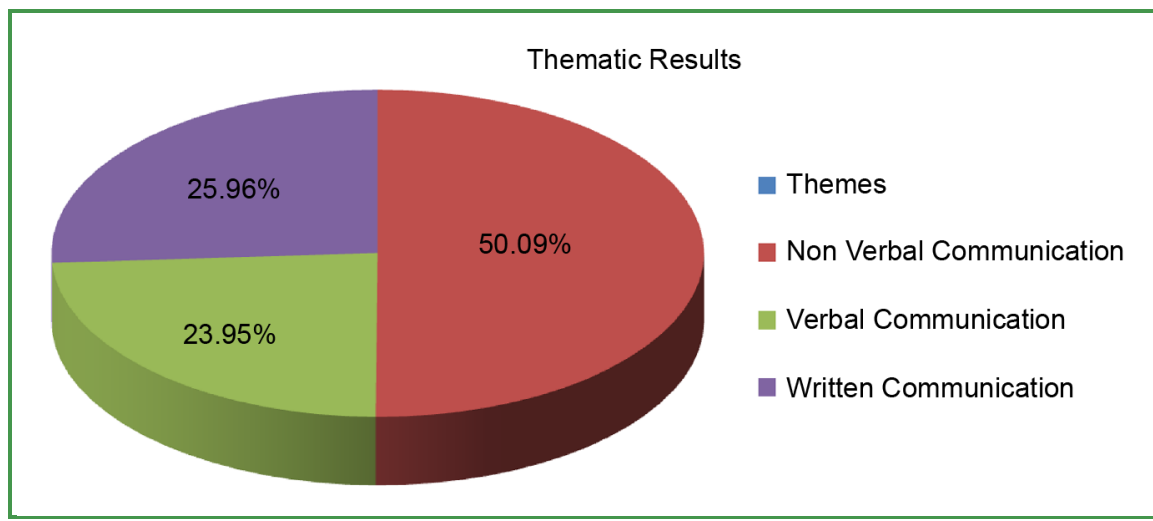

Figure 1. Findings according to major themes studied. 
the highest score (50\%). This was followed by written communication with a score of (26\%). Verbal communication scored (24\%).

Figure 2 shows that Teacher Two scored the highest percentage (21.39\%) as concern observed elements. Teacher Five had the least score with a percentage of (17.73\%). Teacher One recorded a percentage of (20.48\%). Teacher Three had a percentage of (19.56\%) while Teacher Four scored (20.84\%).

\subsection{Findings of Interview}

Concerning nonverbal communication, all the five teachers interviewed were able to define in their own ways nonverbal communication. Teacher I for example stated that "nonverbal communication is a sign language for example eye contact, gestures, body language and hand signals." "The use of nonverbal communication permits pupils to participate effectively in the learning process as sign actions speaks more. The use of didactic resources reduces talking in the teaching learning process but encourages effective participation as pupils react more to what they see than to what they hear." According to Teacher 2, "nonverbal communication is communication with gestures like eye contact, physical appearance and others. Gestures stimulate thinking as the learners become conscious of the expectations of the lesson or particular activity. Nonverbal communication is centred on the use of teaching aids as guides." Teacher 3 pointed out that "nonverbal communication is communication using gestures. It supports active learning as the teacher makes more use of sign language and teaching materials than oral communication." Teacher 4 agreed with the others that "nonverbal communication refers to the teachers' use of gestures in the teaching learning process." Teacher 5 affirmed that "nonverbal communication in the classroom has two sides, kinestics and proxemics. The use of gestures such as eye contact, hand signals help pupils to participate effectively in the learning experience."

As for verbal communication, teacher 1 defines verbal communication as "the use of oral communication. In verbal communication, the teacher also makes use of didactic resources to facilitate the learning process. It promotes confidence

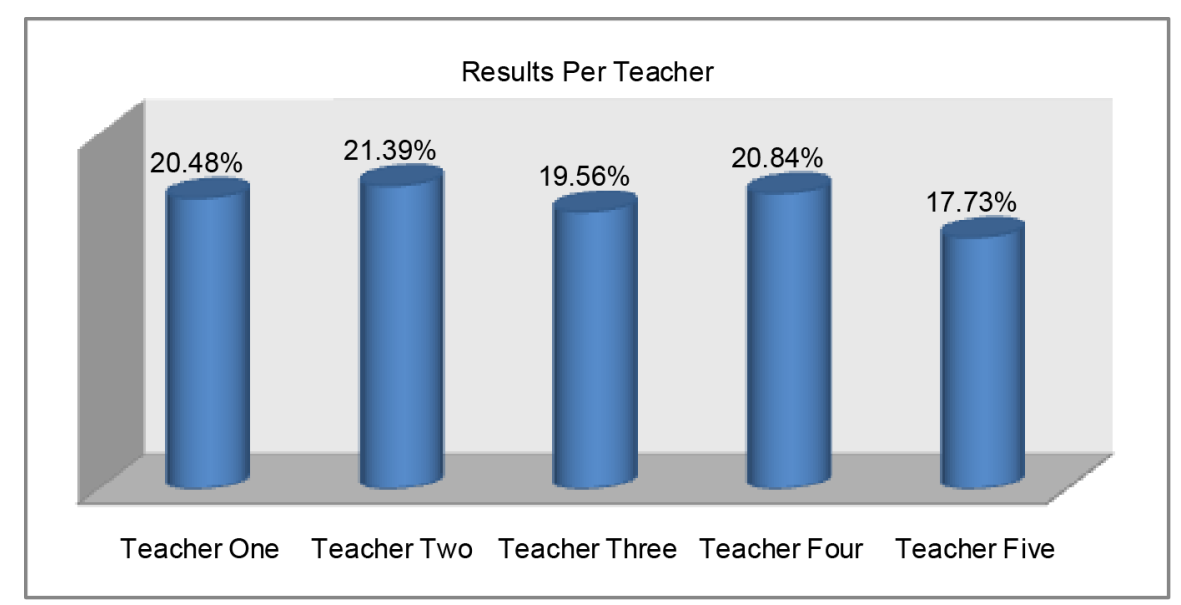

Figure 2. Findings of the study per teacher. 
and active participation in the classroom as pupils have the opportunity to discuss with their teacher. Discussions amongst peers can help the teacher to measure the learning that has taken place." According to Teacher 2, "verbal communication is all about people exchanging words. According to her, teachers should use language that is understood by the learner for instruction. They should speak with confidence, be explicit and precise. Pupils participate actively during the teaching and learning process when the teacher uses verbal communication." Teacher 3 Self-confined that "verbal communication in the classroom is when the teacher speaks and pupils respond and discussions amongst peers. With this kind of communication, the teacher is able to know whether the pupils have understood the lesson or not." Teacher 4 holds the believed that "verbal communication is oral communication between two or more people. According to her, it influences participation in the classroom as pupils have the possibility to work in groups, exchange ideas and help one another in the lesson." To Teacher 5, "verbal communication is the exchange of words among people. It influences participation through processes such as listening, speaking, and confidence. It helps pupils to develop fluency in oral expression as they interact with the teacher and peers."

As concern written communication, Teacher 1 defines it as "pupils' expression in writing. Examples of skills in this kind of communication include grammar, spelling and punctuation." To her, "written communication can influence pupils participation and retention in the classroom as they have the possibility to see and read text material." On her part, Teacher 2 pointed out that "written communication is the presentation of information in writing for others to read and understand particular concepts or ideas." To her, "written communication is the best form of communication as it supports language development and influences cultures. The use of grammatical skills such as nouns, verbs, adverbs, punctuations is given particular attention in written communication. Teacher 3 stated that "written communication helps pupils to express their talents in writing. It influences learning as they are able to demonstrate their grammatical skills, spellings, punctuations etc." Teacher 4 affirmed that "written communication in the classroom consists of grammar, spelling and punctuations." According to her, "when used effectively, pupils are able to retain what is learnt for a longer time and can replicate it in other learning situations." To Teacher 5, "written communication focuses on grammar and punctuation." She further explains that "in grammar, teachers make use of nouns, verbs adverbs, adjectives, conjugation while in punctuation, emphasis is laid on the use of comma, full stop, dash, question marks. Pupils have the possibility to take down the written text in their exercise books and continue learning at home."

\section{Analysis and Discussions of Findings}

\subsection{Nonverbal Communication}

The inquiry on non-verbal communication in the study was centred on teachers' 
use of classroom communication techniques such as kinetics (gestures, staring, beckoning, and body movements) and proxemics (hand signals, charts, sand tray, shopping corner and real objects). The findings obtained from both observation and interview revealed that nonverbal communication has the highest influence on pupils' participation in the learning process. Nonverbal communication with respect to pupils' participation in the learning process had the highest tally scoring (50.09\%). Body movements, a determinant of nonverbal communication classified under kinetics had the highest frequency scoring (7.68\%). Still in the same construct under proxemics, real objects scored a percentage of (7.13\%). This was in accord with the results of the interview. The responses obtained on the question of nonverbal communication revealed that teachers have a good understanding of the concept and use frequently in the classroom as seen on Table 2. All the five (5) teachers who took part in the study affirmed that nonverbal communication contributes to pupils' learning in the primary school. Teachers have the duty to vary their communication techniques in the classroom. Nonverbal communication is very effective when it comes to instilling discipline and laying emphasis on important concepts and procedures during the teaching and learning process in the classroom.

\subsection{Verbal Communication}

The investigation on verbal communication was focused on teachers' use of speech techniques (clarity, duration, confidence and art of listening). The findings obtained from both observation and interview to an extent revealed that the use of verbal communication had the least influence on pupils' participation in the learning process in primary school. The use of verbal communication following the results of the observation had the least tally scoring (23.95\%). However, confidence, a determinant of verbal communication in the classroom categorized under speech had the highest frequency scoring (6.76\%) (see Table 2). From all the observations, findings indicated that teachers do not use verbal communication technique so well as compared to the other communication techniques in the classroom. The results obtained from observation were in contrast with the findings of the interview where all the teachers demonstrated a good mastery on the question of verbal communication and pupils' participation in the learning process. Teachers have the responsibility to always talk to the pupils during the teaching and learning process. The manner in which the teacher speaks to the pupils during the lesson, determines the kinds of interactions that will take place in the classroom. Verbal communication supports the other communication techniques and intend determine the instructional process. It also adds more meaning to the instructional resources used by the teacher in explaining specific concepts and theories.

\subsection{Written Communication}

As for written communication, the researcher sought to find out teachers' use of 
grammar (nouns, verbs and adverbs), punctuation (parentheses, colons, hyphens and apostrophes) during their teaching in class. The findings obtained from both observation and interview revealed that written communication has an influence on pupils' participation in the learning process in primary school. The use of written communication with respect to participation in the learning process following the results of the observation had a low tally as compared to nonverbal communication scoring $(25.96 \%)$. The use of Colons as a factor of punctuation classified under written communication technique had the highest frequency with a percentage of (5.12\%) in that category. In the same vein, the use of nouns classified under grammar as a determinant of written communication technique had the highest percentage of (5.67\%). Notwithstanding, this result was in contrast with the findings obtained from interview where all the five (5) teachers had a positive response on the question of written communication and pupils' participation in the learning process. From the different discussions, teachers made it clear that the usage of written communication contributes to pupils' participation in the learning process in the classroom. The use of appropriate grammar and punctuation is a vital component in language. Language as an important medium of communication in the classroom influences culture and culture plays a vital role on how pupils acquire competences. Thus written communication determines the effectiveness of the instructional processes and procedures. Teachers are expected to use concepts, words and language that can be understood by the pupils.

\section{Conclusion and Recommendations}

Overall, findings of this study revealed that classroom communication techniques influence pupils' participation in the learning process. The results have shown that non-verbal communication, verbal communication and written communication contributes to learners' participation in the learning process but with differing scores. The overall analysis of observation and interview on classroom communication techniques and pupils' participation in the learning process revealed interesting results. Results have shown that teachers use a lot of non-verbal communication behaviours in their classrooms. This was followed by written communication and verbal communication respectively. Findings of the study offer new evidence as well that classroom communication techniques play a vital role in the participation of learners in the learning process in nursery schools. Classroom communication is key for teachers to interact with the learners and for learners to interact with the learning content. It also helps teachers to express thoughts, feelings and subject matter.

Based on the findings of this study recommendations are made to teachers to construct and use appropriate communication behaviours in teaching in order to help all the kids to develop their thinking skills including those with exceptionalities. Teachers should be trained on classroom communication techniques appropriate for nursery and primary schools while in teacher training schools. 
Classroom communications techniques have the potential not only to motivate kids to learn but can also address the diverse needs of the children in the classroom. Teachers should be trained on the development of visual tools. Schools should be equipped with adequate and relevant visual tools. In-service training programs on visual education curriculum should be organized regularly for all the teachers. The study was limited in terms of scope and the application of qualitative research as the dominant approach. The study suggests further research on the same subject and related classroom techniques and practices on a larger scale with a larger sample. Immense thanks goes to all the teachers who participated in this study. Thanks also go to all the authors whose works have been used in this study.

\section{References}

Bandura, A. (1977). Self-Efficacy: Toward a Unifying Theory of Behavioral Change. Psychological Review, 84, 191-215.

Bandura, A. (1997). Self-Efficacy: The Exercise of Control. New York: W. H. Freeman.

Bottino, M. R. (2004). The Evolution of ICT-Based Learning Environments: Which Perspectives for the School of the Future? British Journal of Educational Technology, 35, 553-567. https://doi.org/10.1111/j.0007-1013.2004.00413.x

Bredekamp, S., \& Copple, C. (1997). Developmentally Appropriate Practice in Early Childhood Programs (Revised Edition). Washington, DC: NAEYC.

Brown, J. S., Collins, A., \& Duguid, P. (1989). Situated Cognition and the Culture of Learning. Educational Research, 18, 32-42.

https://doi.org/10.3102/0013189X018001032

Crook, C. (2001). The Social Character of Knowing and Learning: Implications of Cultural Psychology for Educational Technology. Journal of Information Technology for Teacher Education, 10, 19-36. https://doi.org/10.1080/14759390100200100

Ellis, M., \& Abrams, L. D. (2009). Personality Theories: Critical Perspectives. Thousand Oaks, CA: Sage Publications.

Glickman, C. D. (1985). Supervision of Instruction: A developmental Approach. Boston, London, Sydney, Toronto: Allyn and Bacon, Inc..

Kail, R. V., \& Cavanaugh, J. C. (2010). Human Development: A Life-Span View (5th ed.). Wadsworth: Cengage Learning.

Kauchak, D., \& Eggen, P. (1998). Learning and Teaching: Research-Based Methods (3rd ed.). Boston, MA: Allyn and Bacon.

Ministry of National Education (2000). National Syllabuses for English Speaking Primary Schools in Cameroon. Yaounde: L Imprimerie Saint JOHN.

Reed, A. J. S., \& Bergemann, V. E. (1995). A Guide to Observation and Participation in the Classroom: An introduction to Education (2nd ed.). Asheville, NC: The Dushkin Publishing Group, Inc.

Santrock, J. W. (2004) Educational Psychology(2nd ed.). New York: McGraw-Hill.

Tambo, L. I. (2012). Principles and Methods of Teaching. Limbe: ANUCAM Publisher.

Tisdell, E. J. (2005). Feminism. In L. M. English (Ed.), International Encyclopaedia of Adult Education. London: Palgrave.

Tu, C.-H. (2000) On-Line Learning Migration: From Social Learning Theory to Social 
Presence Theory in a CMC Environment. Journal of Network and Computer Application, 23, 27-37. https://doi.org/10.1006/jnca.1999.0099

Wang, Y. (2009). Impact of Lev Vygotsky on Special Education. Canadian Social Science, 5, 100-103.

World Bank (2018). World Development Report 2018: Learning to Realize Education's Promise. Washington, DC: World Bank. 